\title{
Erratum to: Long-term success of dental implant-supported dentures in postirradiated patients treated for neoplasms of the maxillofacial skeleton: a retrospective study
}

Yiqun $\mathrm{Wu}^{1} \cdot$ Wei Huang ${ }^{1} \cdot$ Zhiyong Zhang $^{1} \cdot{\text { Zhiyuan } \text { Zhang }^{2} \cdot \text { Duohong Zou }}^{1}$

Published online: 21 June 2017

(C) Springer-Verlag Berlin Heidelberg 2017

Erratum to: Clin Oral Invest

DOI 10.1007/s00784-016-1753-z

The originally published article contains a wrong Fig. 1. The correct Fig. 1 is provided here:

There is also a change in the affiliations of Yiqun $\mathrm{Wu}$ and Duohong Zou which is reflected here.

The online version of the original article can be found at http://dx.doi.org/ 10.1007/s00784-016-1753-z

Duohong Zou

zouduohongyy@126.com

1 Department of Second Dental Clinic, Ninth People's Hospital Affiliated with Shanghai Jiao Tong University, School of Medicine, Shanghai Key Laboratory of Stomatology, Shanghai 200001, People's Republic of China

2 Department of Oral and Maxillofacial Surgery, School of Medicine, Ninth People's Hospital affiliated with Shanghai Jiao Tong

University, Shanghai, China 
Fig. 1 Clinical view of a maxilla with a combination of three regular implants and one zygomatic implant supported bar overdenture (a-d RPD with bar attachment)
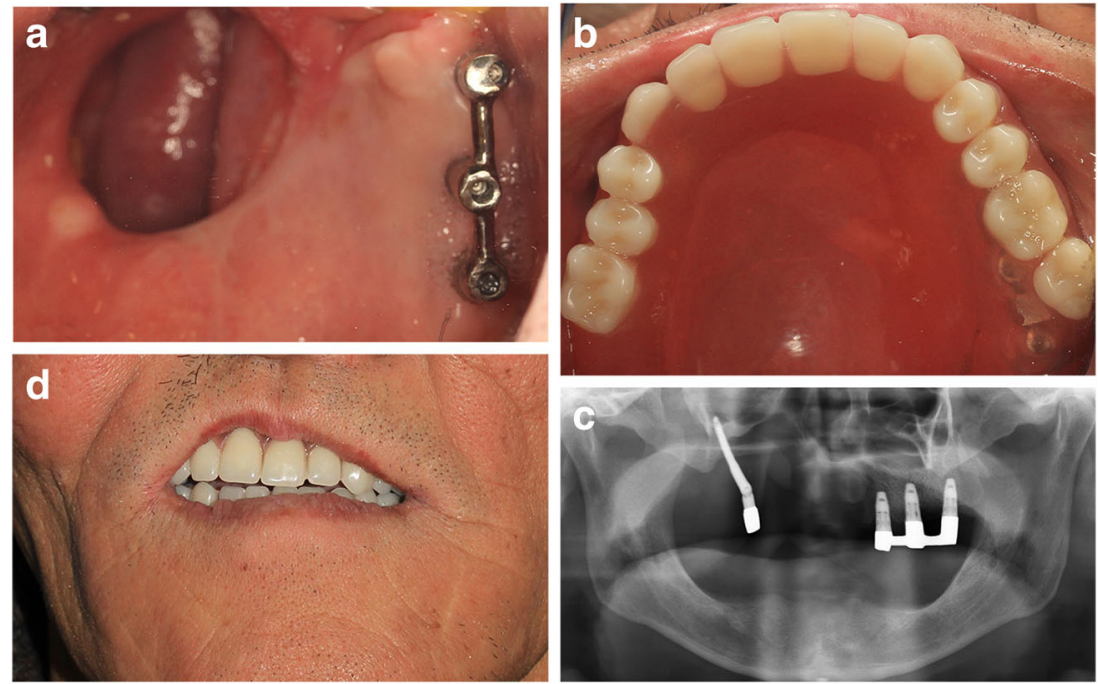